ISSN 1112-9867

Available online at

http://www.jfas.info

\title{
POLYPROPYLENE-MODIFIED KAOLINITE COMPOSITES: EFFECT OF CHEMICAL MODIFICATION ON MECHANICAL, THERMAL AND MORPHOLOGICAL PROPERTIES
}

\author{
O. Meziane* , A. Bensedira, M. Guessoum and N. Haddaoui \\ Laboratory: Physical-Chemistry of High Polymers (LPCHP) \\ Department of Process Engineering, Faculty of Technology \\ Ferhat Abbas University - Setif 19000, Algeria
}

Received: 18 November 2015 / Accepted: 21 April 2016 / Published online: 01 May 2016

\begin{abstract}
The intercalation of kaolinite with an ammonium salt was performed. Untreated and treated kaolinite samples were examined by X-ray diffraction (XRD). PP/kaolinite compounds were prepared by the melt intercalation method. The effects of modified clay on properties of the prepared composites were studied. The XRD results showed that the treatment with the ammonium salt caused the return to the initial state of the clay. The thermogravimetric analysis thermograms (TGA) marked an increase in thermal degradation of the composites, while the differential scanning calorimetric (DSC) results showed the decrease of the crystallization temperature and the melting point in presence of clay in the matrix owing to the fact that the filler acts as reinforcing effect. The mechanical properties of the composites exhibited important variations, the morphology of the composites was further studied using scanning electron microscopy (SEM) and showed poor dispersion of used nanoclay in PP matrix.
\end{abstract}

Keywords: polypropylene; composites; kaolinite; surface treatment; melt intercalation.

Author Correspondence, e-mail: meziane.ouahiba@yahoo.com

doi: http://dx.doi.org/10.4314/jfas.v8i2.21

\section{INTRODUCTION}

Composites materials and polymers composites in particular are amongst the most widely used and constitute an important class of material. A composite material is chosen wherever 
there is an advantage in combining the properties of two or more materials and to improve these properties, such as mechanical, thermal and barrier properties of the final polymer product.

Mineral fillers have, since the beginning, made an important contribution to the spectacular growth of thermoplastic polymers composites. This emphasis on filled polymer composites is due to a combination of factors. Addition of mineral filler can enhance the processing of the polymer at the same time as improving the balance of properties such as strength, stiffness, cost, appearance and flammability, which are the principal limitations of the bulk thermoplastics. The effects of fillers on the mechanical and other properties of the composites depend on their shape, particle and aggregate sizes, surf ace characteristics, and degree of dispersion [1, 2].

Obviously, there is a large incentive to use all the commercially and inexpensive important thermoplastic polymers, but, in volume terms, the principal markets are in PVC and polyolefins for as many applications as possible. Polypropylene is one of the most versatile commodity thermoplastics with low cost, high thermal stability and low density. The polymer is used in a wide variety of applications, including packaging, textiles, reusable containers of various types, laboratory equipment, automotive .... To improve some of its properties and thus widen its application range, blending with other polymers and/or fillers is the alternative that is usually employed in order to increase its strength, impact resistance and toughness. Among the inorganic fillers that are used to improve PP properties, clays are recognized to get several beneficial variations on stiffness, hardness, toughness and heat resistance [3, 4].

Kaolinite is a common phyllosilicate mineral, with a general chemical formulation $\mathrm{Al}_{2} \mathrm{Si}_{2} \mathrm{O}_{5}(\mathrm{OH})_{4}$. This clay has 1:1 dioctahedral structure which is composed of tetrahedral sheets $\mathrm{SiO}_{4}$ and octatedral sheets $\left(\mathrm{Al}_{2}(\mathrm{OH})_{4}\right)$. Individual layered consists of both sheets which are closely connected by hydrogen bond between surface hydroxyl groups on the octahedral side and the basal oxygen atoms on the tetrahedral side. The most reactive functional groups in kaolinite are hydroxyl groups, which are capable of taking part in many chemical reactions as well as ion exchange processes [5-7].

Because of hydrophobic properties of kaolinite and hydrophilic character of polymer (e.g., polypropylene), poor adhesion occurred between the filler surface and the matrix, in addition, achieving uniform dispersion of the fillers tended to be difficult. Therefore, the surface modification of kaolinite is necessary [6-8], it can be achieved either by the use of coupling agents, or by the insertion of small molecules agents, in the interlayer of the kaolinite, such as 
dimethylsulfoxide (DMSO), formamide, hydrazine potassium acetate, and urea [9-10]. The separation of kaolinite layers results in particle size reducing and an increase of the specific surface area and the basal spacing of the clay which may facilitate the intercalation of polymer chains between its platelets and the composite materials exhibit remarkable improvements in materials properties compared with the virgin polymer [11].

The influence of surface treatments of kaolinite with an alkylammonium salt on the mechanical morphological and thermal properties of polypropylene (PP) was studied in present work.

\section{EXPERIMENTAL}

\subsection{Materials}

The polypropylene (PP) used in this study is a statistic copolymer grade "Moplen RP 320H", obtained from Basell. The melt flow index (MFI) reported to be $2.30 \mathrm{~g} / 10 \mathrm{~min}$ at $190{ }^{\circ} \mathrm{C}$ with the density of $0.9 \mathrm{~g} / \mathrm{cm}^{3}$.

The raw kaolinite used to prepare PP/kaolinite composite, consisted of small-diameter $(\leq 45$ $\mu \mathrm{m})$ particles that had perfect crystallization and high purity. Its chemical composition was determined by chemical analysis $\left(\mathrm{SiO}_{2}: 50.44, \mathrm{Al}_{2} \mathrm{O}_{3}: 28.30, \mathrm{CaO}: 1.10, \mathrm{MgO}: 0.50\right.$, $\mathrm{Fe}_{2} \mathrm{O}_{3}: 2.29$, with a loss on ignition (LOI) of 10.01). The kaolinite was modified with an alkylammonium is a hexadecyl trimethyl ammonium chloride abbreviated as (HDTMA), purchased from Aldrich, and having the following chemical structure: $\mathrm{CH}_{3} \quad\left(\mathrm{CH}_{2}\right)_{15} \mathrm{~N}$ $\left(\mathrm{CH}_{3}\right)_{3} \mathrm{Cl}$.

\subsection{Kaolinite treatments}

The kaolinite used in this study was already intercalated with dimethylformamide (DMF). The resulting material was subjected to a reaction in a solution containing the ammonium salt (HDTMA) at a temperature of $80^{\circ} \mathrm{C}$ for 24 hours. After that, the clay was filtered and dried then stored.

\subsection{Preparation of Composites}

An internal mixer (Haake Rheocord) was used to prepare the required composites, respectively, PP/TK and PP/UK, with polypropylene matrix and the treated and untreated kaolinite amounts varying from 1 to 5 parts per hundred resins (phr), the mixing temperature was kept at $190^{\circ} \mathrm{C}$, the rotation speed set at $30 \mathrm{rpm}$ for a period of 10 minutes. 


\subsection{CHARACTERIZATION METHODS}

\subsubsection{X-ray diffraction (XRD)}

XRD was used to study the modified and unmodified kaolin using XPERT diffractometer equipped with $\mathrm{Cu}-\mathrm{k} \alpha$ radiation $(\lambda=0.154 \mathrm{~nm})$ at room temperature. The scans were taken in a 2 range from 4 to $30^{\circ}$, with $0.02^{\circ}$ step size and the counting time of one scan $5 \mathrm{~s}$.

\subsubsection{Melt flow index (MFI)}

Melt flow indices of polypropylene matrix and PP composites with the treated and untreated kaolinite amounts varying from 1 to 5 parts per hundred resins (phr) were measured according to ASTM D 1238 using MFI apparatus ( Melt - Indexer modèle 5), under the condition of $2.16 \mathrm{~kg}$ load at the temperature of $230^{\circ} \mathrm{C}$.

\subsubsection{Scanning electron microscopy (SEM)}

It was employed to observe the morphology such as filler dispersion inside the polymeric materials and interfacial adhesion of the components. The surface of film was coated with thin layer of $\mathrm{Au}$, with a SEM-coating device and then experimental using SEM with acceleration voltage of $20 \mathrm{kV}$.

\subsubsection{Differential scanning calorimetric (DSC)}

DSC (TA Instrument) was used to study the crystallization and melting behavior. The sample were heated from ambient temperature to $250^{\circ} \mathrm{C}$ under nitrogen atmosphere, at heating rate of $10^{\circ} \mathrm{C} / \mathrm{min}$ and kept at this temperature for $5 \mathrm{~min}$ before cooling down in order to assure that the materials melted uniformly and eliminating thermal history. The samples were then cooled down to room temperature at cooling rate of $10^{\circ} \mathrm{C} / \mathrm{min}$ under nitrogen atmosphere.

Crystallization temperature $\left(\mathrm{T}_{\mathrm{c}}\right)$ and melting temperature $\left(\mathrm{T}_{\mathrm{m}}\right)$ were recorded on the thermograms. In order to estimate the crystallinity $\%\left(\chi_{c}\right)$, the following equation was used [12]:

$$
\chi_{C}(\%)=\frac{\Delta H_{c}}{\Delta H_{c}^{0}} \times 100
$$

Where, $\Delta \mathrm{H}_{\mathrm{c}}$ is the crystallization melting enthalpy of the sample analyzed $[\mathrm{J} / \mathrm{g}]$, and $\Delta H_{c}^{0}$ is reference value that represents the crystallization melting enthalpy for $100 \%$ crystalline Polypropylene $\left(\Delta H_{c}^{0}\right.$ is $\left.165 \mathrm{~J} / \mathrm{g}\right)$ was used [13].

\subsubsection{Thermogravimetric analysis (TGA)}

The thermal characteristics of the samples was determined by thermal gravimetric analysis (TGA) using a TGA Q500 apparatus with a heating rates of $20^{\circ} \mathrm{C} / \mathrm{min}$ in air The isothermal 
degradation experiment was performed from 20 to $550^{\circ} \mathrm{C}$. From thermograms giving the variations of the weight loss derivative as a function of temperature, we estimated the temperatures at which starts and finishes the degradation process $\mathrm{T}_{\mathrm{d} 0}$ and $\mathrm{T}_{\mathrm{df}}$, respectively, as well as, the temperature at the maximum weight loss and the residual mass, $T_{\text {dmax }}$ and $M_{\text {res }}$, respectively.

\subsubsection{Mechanical properties}

Notched Izod impact strengths were measured on compressed samples according to the norm ASTM D256, using a Resil Impactor pendulum instrument to characterize the tensile characteristics of the hompolymer and its composites, namely, the stress and the elongation at yielding and at break $\left(\sigma_{\mathrm{y}}\right.$ and $\left.\varepsilon_{\mathrm{y}}\right)$ and $\left(\sigma_{\mathrm{r}}\right.$ and $\left.\varepsilon_{\mathrm{r}}\right)$, respectively, measurements were performed according to the norm ASTM D638, at a cross-head speed of $30 \mathrm{~mm} / \mathrm{min}$ on dumbbell samples using a Zwick Material prufung 1445.

\section{RESULTS AND DISCUSSION}

\subsection{XRD analysis}

The XRD was used to observe intercalation process into kaolinite. 'Figure1' (curve b), depicting the XRD pattern of the kaolinite treated with the alkylammonium salt in aqueous solution, shows that the treatment does not produce any detectable structural changes on the interlayer spacing of the clay, with a few decrease in intensity of $\mathrm{d}_{001}$ basal diffraction of kaolinite.

So, it is clear that the ammonium salt molecules interacted with the kaolinite hydroxyls groups involved at the surface of the clay particles and not with those situated in the interlayer space.

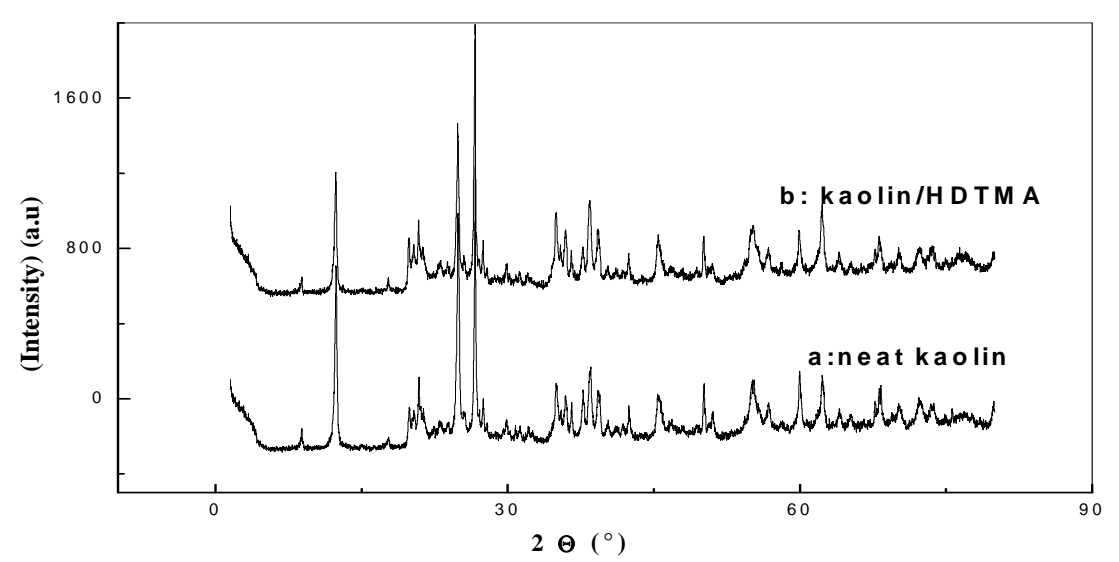

Fig.1. X-ray diffraction curves of neat kaolinite and kaolin/HDTMA mixtures 


\subsection{Melt flow index (MFI)}

Figure 2 represents the variations of melt flow index (MFI) of PP/UK and PP/TK composites. MFI has marginal reduction of 2.33 to $1.76 \mathrm{~g} / 10 \mathrm{~min}$ of PP/UK and of 2.33 to 2.68 for PP/TK, respectively, due to addition of untreated and treated kaolinite. And according to the figure, we observe a slight variation of the values of the index of fluidity compared to that of the matrix. This can be due to the low content of kaolin and the formation of agglomerates within the matrix, in consequence of the bad dispersion of the particles of the load. These agglomerates can prevent the flow of polymer. Also, according to the figure 2 and table 1 , it is noted that the MFI values of PP/TK are higher than those of the PP/UK composites, this increase can be due to the treatment of used clay, so, the use of alkylammonium salts for the treatment of kaolinite facilitates the flow of the chains of the matrix PP. The MFI values of PP and its composites are shown in table 1.

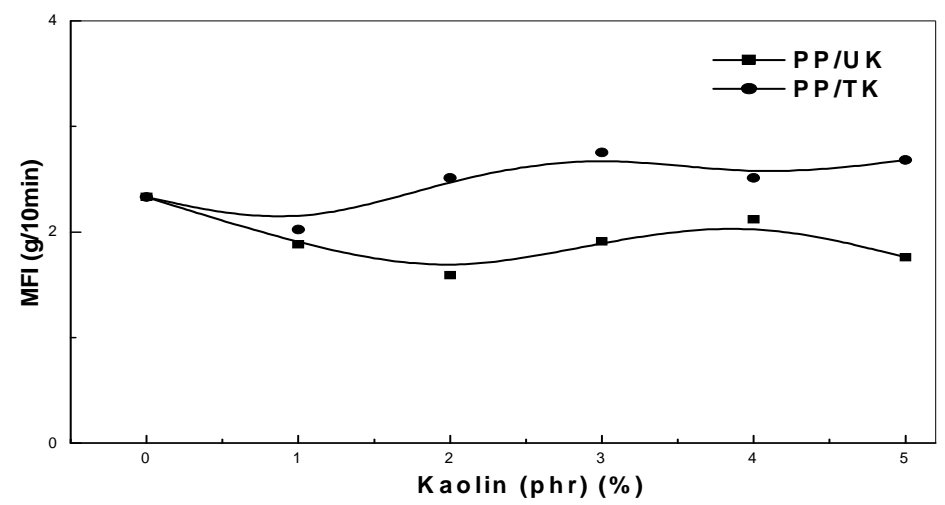

Fig.2. PP composites melt flow index variations as a function of treated and untreated kaolin concentration

Table 1. MFI values of PP and its composites

\begin{tabular}{ccc}
\hline Kaolin (phr) & \multicolumn{2}{c}{ MFI (g/ 10min) } \\
\cline { 2 - 3 } & PP/UK & PP/TK \\
\hline 0 & 2.33 & 2.33 \\
\hline 1 & 1.88 & 2.02 \\
\hline 2 & 1.59 & 2.51 \\
\hline 3 & 1.91 & 2.75 \\
\hline 4 & 2.12 & 2.51 \\
\hline 5 & 1.76 & 2.68 \\
\hline
\end{tabular}




\subsection{Morphology}

The dispersion of clay in polypropylene was evaluated by scanning electron microscopy (SEM). Figure 3 is the SEM micrograph of PP/UK and PP/TK filled with 4 phr, it shows that the untreated kaolinite (UK) and treated kaolinite (TK) is not evenly dispersed in the throughout matrix; However, a deeper investigation, specifically performed on filler aggregates for all composites, suggests a swollen lamellar structure within themselves, with the presence of large and small agglomerates and poor adhesion to the polymer. It is very difficult to estimate the size of the aggregates because they are non-isometric and randomly dispersed in matrix. The size of the aggregates is, therefore, strongly dependent on orientation of particles. However, the size of aggregates in PP/UK is larger than the size of aggregates in PP/TK. However, utilization of the treatment kaolinite improved dispersion and decrease the size of aggregation.
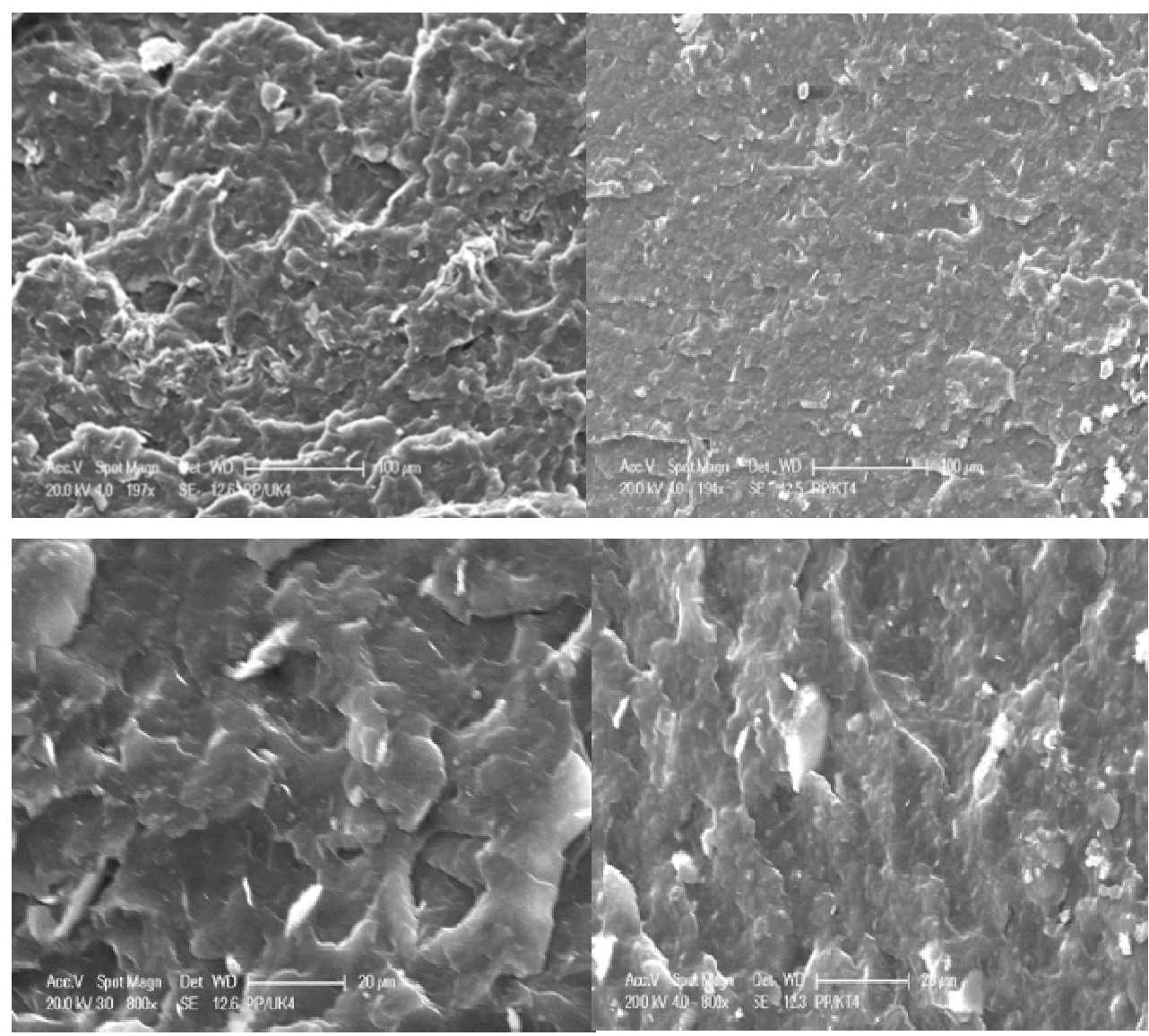

$-a-$

-b

Fig.3. SEM micrographs of PP composites filled with 4 phr of:

a) Treated kaolinite b) Untreated kaolinite at different magnitudes 


\subsection{Melting and Crystallization Behaviors}

Figures 4 and 5 compare the DSC cooling thermograms of neat PP with its various composites. In (Figures 4), the effects of adding unmodified kaolin on the crystallization of PP are evident.

The crystallization peak temperature $\mathrm{T}_{\mathrm{c}}$ (temperature at the exotherm maximum) of PP was slightly shifted as kaolin is added. The little variation in the crystallization temperature after introduction of the filler means that higher undercooling of the melt is necessary for the crystallization to occur ${ }^{14}$; we believe that the reason of this behavior is the strong influence of the kaolinite on the chain dynamics. Although fillers usually act as nucleation centers [15], the crystallization in the present system is slowed down as a result of lower chain mobility.

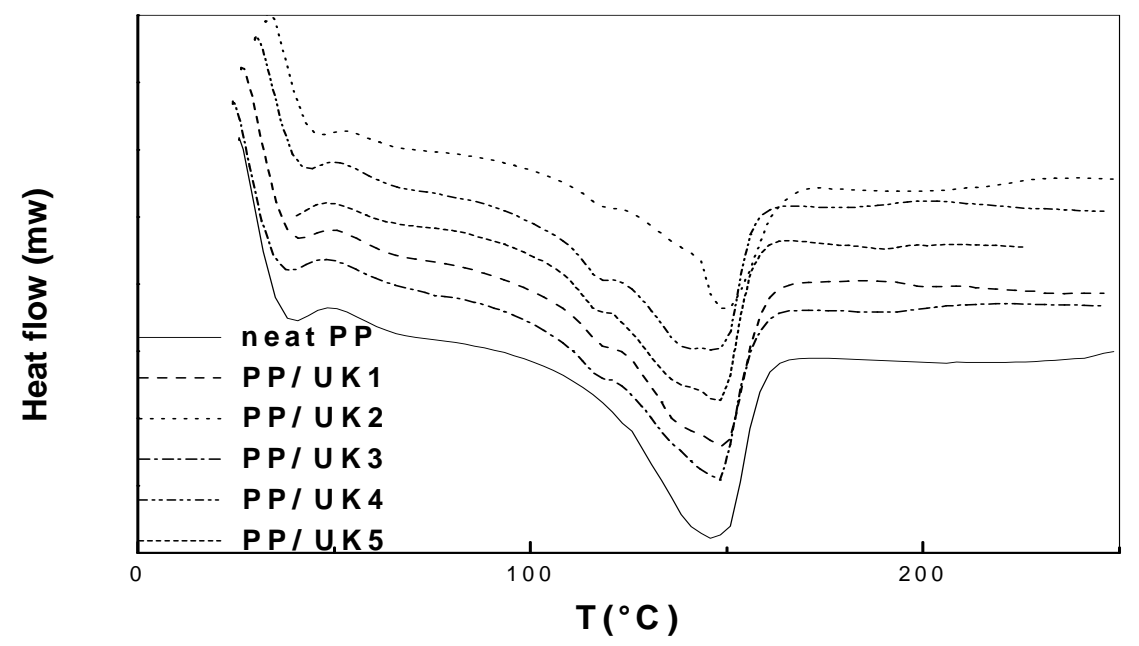

Fig.4. DSC thermograms of PP/untreated kaolin

Figure 5 depicts the DSC cooling thermograms of neat PP and its ammonium modified kaolin composites. The crystallization retarding effect of the filler is still observed, but it is more obvious for the clay loadings of 4 and $5 \mathrm{phr}$, so the shifting of the crystallization temperature increases proportionally to the clay concentration. When comparing the thermograms of the composites including the three first modified kaolin loadings (1, 2, and $3 \mathrm{phr}$ ), with those of the composites containing the equivalent rates of the unmodified clay, we notice that the values of $\mathrm{T}_{\mathrm{c}}$ are slightly lower to the matrix ones but sufficiently higher to those of the composites PP/unmodified kaolin. This fact can merely be linked to the treatment and to the interactions between the kaolinite modified surface and PP chains. Thus, the combined effect of the clay and of the interactions clay/matrix contributes to get an enhanced PP chains 
mobility and consequently a faster crystallization rate and higher crystallization temperatures, relatively to untreated kaolin composites.

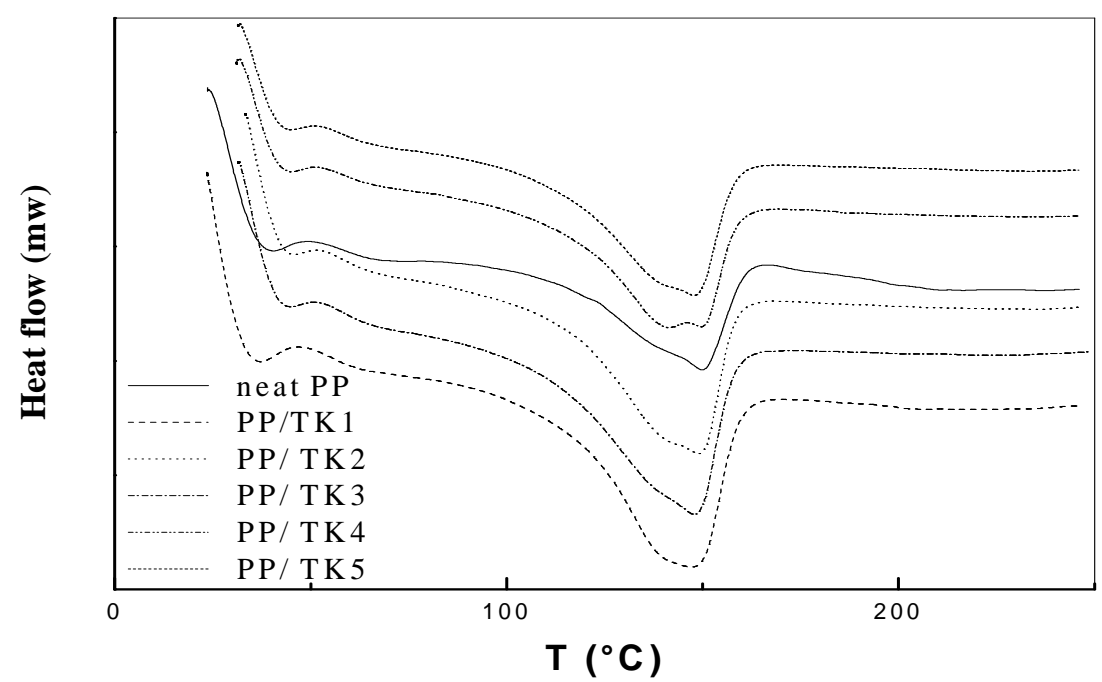

Fig.5. DSC thermograms PP/treated kaolin

The melting peak temperatures $\mathrm{T}_{\mathrm{m}}$ of the untreated and ammonium treated kaolin composites vary trivially with respect to that of neat PP. This result suggests that the addition of small kaolin concentrations and its treatment did not affect the structure and the stability of the formed PP crystals.

These results indicate that the incorporation and the modification of the filler apparently affect the PP crystallization rate, but influence the PP crystallinity only slightly, as it is reported in the Table 2 .

DSC results show no significant differences between pure PP and composites (Table 2). We expected nanoclay act as a nucleating agent and enhance crystallization temperature $\left(\mathrm{T}_{\mathrm{c}}\right)$. Nevertheless, the crystallization capability of nanoclay composites will not be improved if the filler network plays a role to restrict the movement of molecular chains. There are no significant changes in $T_{m}$ and $X_{c}$ between all samples. Therefore, most of nanoparticles are placed in amorphous phase. Additionally, the crystallization heat $\Delta \mathrm{H}_{\mathrm{c}}$ varied in significantly for all the composites samples. 
Table 2. DSC results for Polypropylene and its composites filled with treated and untreated kaolinite

\begin{tabular}{cccccc}
\hline SAMPLES & $\Delta \mathrm{H}_{\mathrm{M}}(\mathrm{J} / \mathrm{g})$ & $\mathrm{T}_{\mathrm{M}}\left({ }^{\circ} \mathrm{C}\right)$ & $\Delta \mathrm{H}_{\mathrm{C}}(\mathrm{J} / \mathrm{g})$ & $\mathrm{T}_{\mathrm{C}}\left({ }^{\circ} \mathrm{C}\right)$ & $\mathrm{X}_{\mathrm{C}}(\%)$ \\
\hline Neat PP & 63 & 145.87 & 68 & 49 & 41 \\
\hline PP/UK1 & 56 & 148.44 & 60 & 49.5 & 36 \\
PP/UK2 & 65 & 148.46 & 65 & 48 & 39 \\
PP/UK3 & 59 & 148.42 & 61 & 49 & 37 \\
PP/UK4 & 54 & 145.98 & 65 & 49 & 39 \\
PP/UK5 & 63 & 148.45 & 65 & 51 & 39 \\
\hline PP/TK1 & 60 & 148.43 & 67 & 50 & 40 \\
PP/TK2 & 63 & 148.44 & 63 & 51 & 38 \\
PP/TK3 & 57 & 148.45 & 58 & 50 & 35 \\
PP/TK4 & 57 & 150.96 & 58 & 52 & 35 \\
PP/TK5 & 59 & 148.45 & 65 & 52 & 39 \\
\hline
\end{tabular}

\subsection{Thermal degradation}

The effect of the nanofiller presence on the thermal stability of the composites was studied by means of thermogravimetry experiments. Figures 6 and 7 report the TGA curves, obtained under air atmosphere, of PP samples and composites which degradation characteristics are reported in the (Table 2).

The degradation of pure polypropylenes takes place in one stage from 250 to $393^{\circ} \mathrm{C}$ with approximately no residual mass.

The PP/untreated kaolin composites showed almost an identical thermal stability and as the PP matrix, they are decomposed on only one stage. All the composites started degradation at $250{ }^{\circ} \mathrm{C}$, however; a noticeable increase is observed on the value of the temperature at which the degradation is achieved $\mathrm{T}_{\mathrm{df}}$. For example, the composite including $5 \mathrm{phr}$ of kaolin begins to degrade at $250{ }^{\circ} \mathrm{C}$ and finished at $405{ }^{\circ} \mathrm{C}$, with a residual mass around $5.5 \%$, which is approximately the clay loading in the composite. $T_{\mathrm{dmax}}$ exhibit the same variations as $\mathrm{T}_{\mathrm{df}}$ because it increases when the kaolin concentration increases. Indeed, $\mathrm{T}_{\mathrm{dmax}}$ varies from $374{ }^{\circ} \mathrm{C}$ for neat PP to $389{ }^{\circ} \mathrm{C}$ for the formulation including $5 \mathrm{phr}$ of kaolinite. These observations suggest that the addition of small amounts of the filler enhances noticeably the thermal stability of the whole material [16]. 
The thermal stability of the PP/modified kaolin composites, exhibited a similar trend as the above ones. All the formulations started degradation around $250^{\circ} \mathrm{C}$ and finishes with a residual mass equivalent to the clay loading in the composites. $\mathrm{T}_{\mathrm{df}}$ and $\mathrm{T}_{\mathrm{dmax}}$ showed an enhancement relative to the matrix, but no variations were noticed when compared to the composites with unmodified clay. So, the thermal stability enhancement is mainly due to the clay.

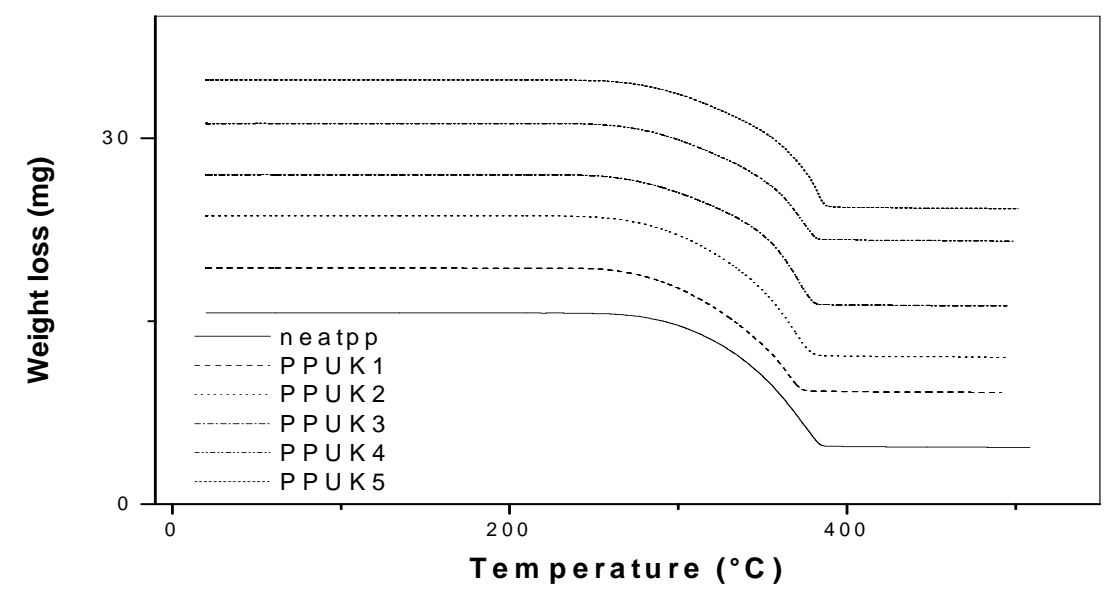

Fig.6. TGA thermograms of neat PP and UK/PP composites

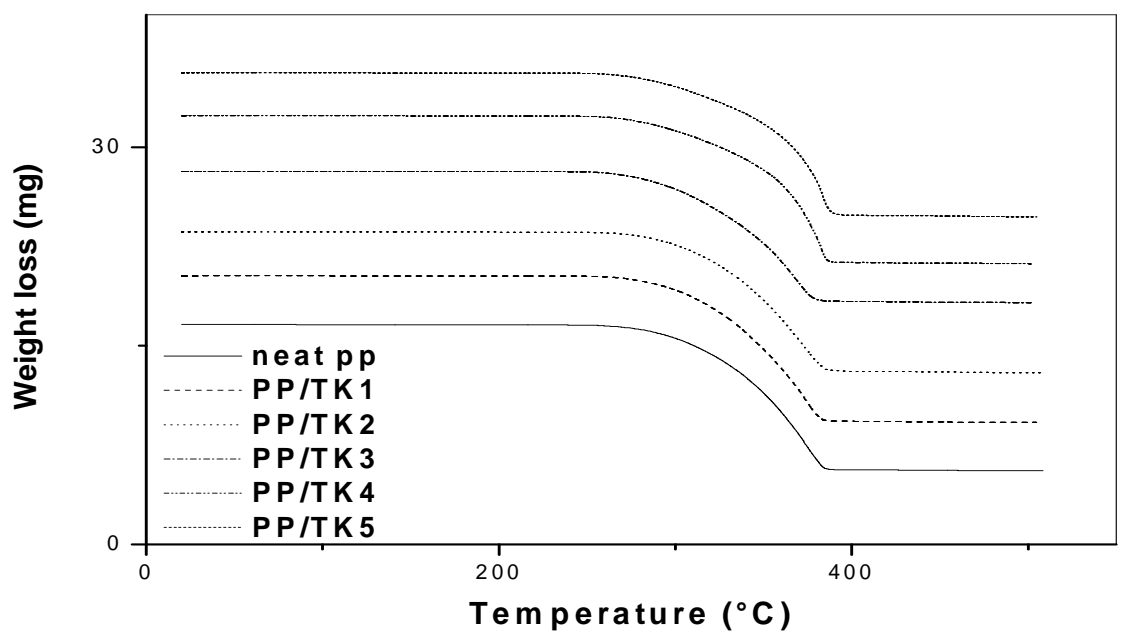

Fig.7. TGA thermograms of PP and TK/PP composites 
Table 3. TGA data for PP samples and its composites filled with treated and untreated kaolinite

\begin{tabular}{ccccc}
\hline Samples & $\mathrm{T}_{\mathrm{d} 0}\left({ }^{\circ} \mathrm{C}\right)$ & $\mathrm{T}_{\mathrm{dmax}}\left({ }^{\circ} \mathrm{C}\right)$ & $\mathrm{T}_{\mathrm{df}}\left({ }^{\circ} \mathrm{C}\right)$ & Residue (WT \%) \\
\hline NEAT PP & 250 & 374 & 393 & 0.02 \\
\hline PP/UK1 & 250 & 380 & 395 & 0.14 \\
PP/UK2 & 249 & 383 & 400 & 0.22 \\
PP/UK3 & 252 & 386 & 404 & 0.42 \\
PP/UK4 & 247 & 384 & 403 & 0.39 \\
PP/UK5 & 25 & 389 & 404 & 0.49 \\
\hline PP/TK1 & 252 & 376 & 394 & 0.10 \\
PP/TK2 & 250 & 370 & 398 & 0.20 \\
PP/TK3 & 253 & 377 & 394 & 0.26 \\
PP/TK4 & 250 & 387 & 403 & 0.43 \\
PP/TK5 & 248 & 388 & 404 & 0.50 \\
\hline
\end{tabular}

\subsection{Composites Mechanical properties}

\subsubsection{Composites Impact Strength}

The Izod impact strength variations of the PP composites notched samples filled with modified and unmodified kaolin are illustrated by Figure 8.

It appears that kaolinite incorporation to the thermoplastic matrix causes a marked decrease of its impact strength. This result is explained by the fact that the introduction of the mineral filler engenders an increase of rigidity and causes a high local stress concentration at the inter face filler/matrix, attributed especially to aggregates formation which weakens the strength of all the material. Because of the prominent dominance of these effects, the ammonium kaolinite treatment effect is not apparent. 


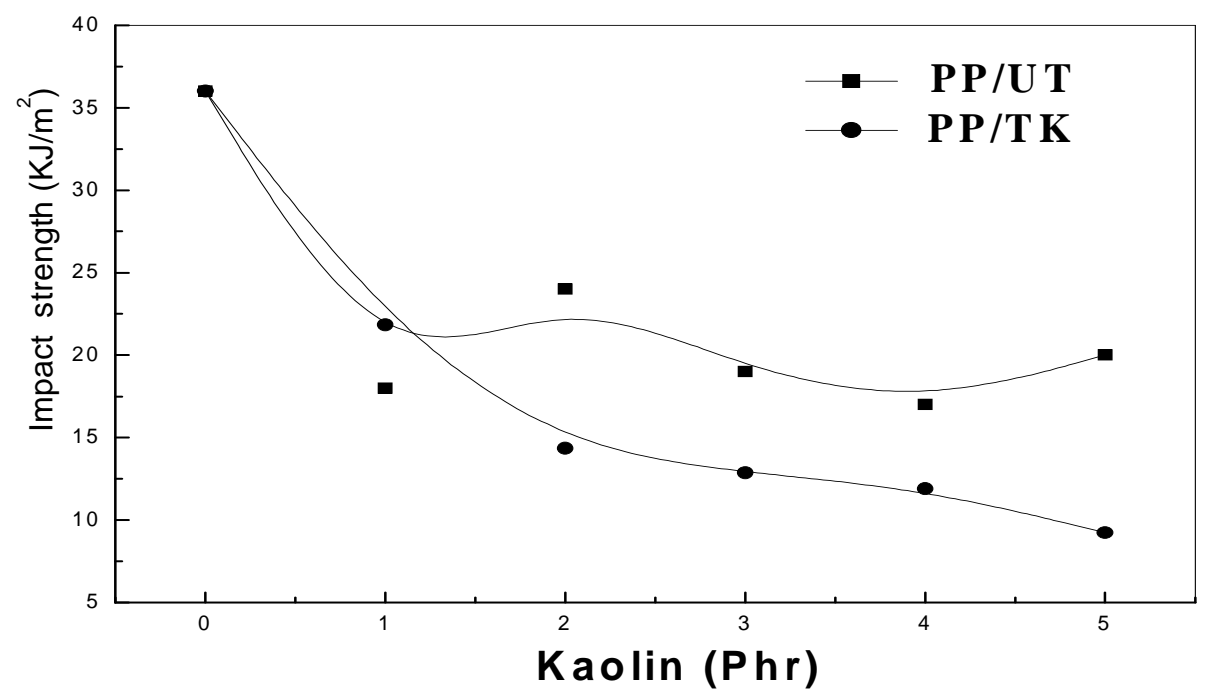

Fig.8. PP composites notched Izod impact strength variations as a function of treated and untreated kaolin concentration

\subsubsection{Composites Tensile Properties}

Figures 9 and 10 depict the tensile characteristics variations for the composites prepared with unmodified kaolin and with kaolin treated with the alkylammonium salt. Thus, it appears from the Figure 9 that the yielding stress and strain values are slightly affected by kaolinite treatment and concentration.

Figure 10 illustrates the variations of the stress and the strain at break as function of the filler rate for the composites with treated and untreated kaolin. The behavior at break of the composites has been markedly affected by the incorporation of the mineral filler. Thus, the strain noticeable decrease occur red from $600 \%$ for the nonfilled PP to a value of $60 \%$ for the composites with $5 \mathrm{phr}$ of untreated kaolin and to $27 \%$ for that containing the same concentration of the filler treated with the alkylammonium salt. The decrease of the strain at break a this filler loading might be due to the decreased deformability at the interface the filler/matrix. 


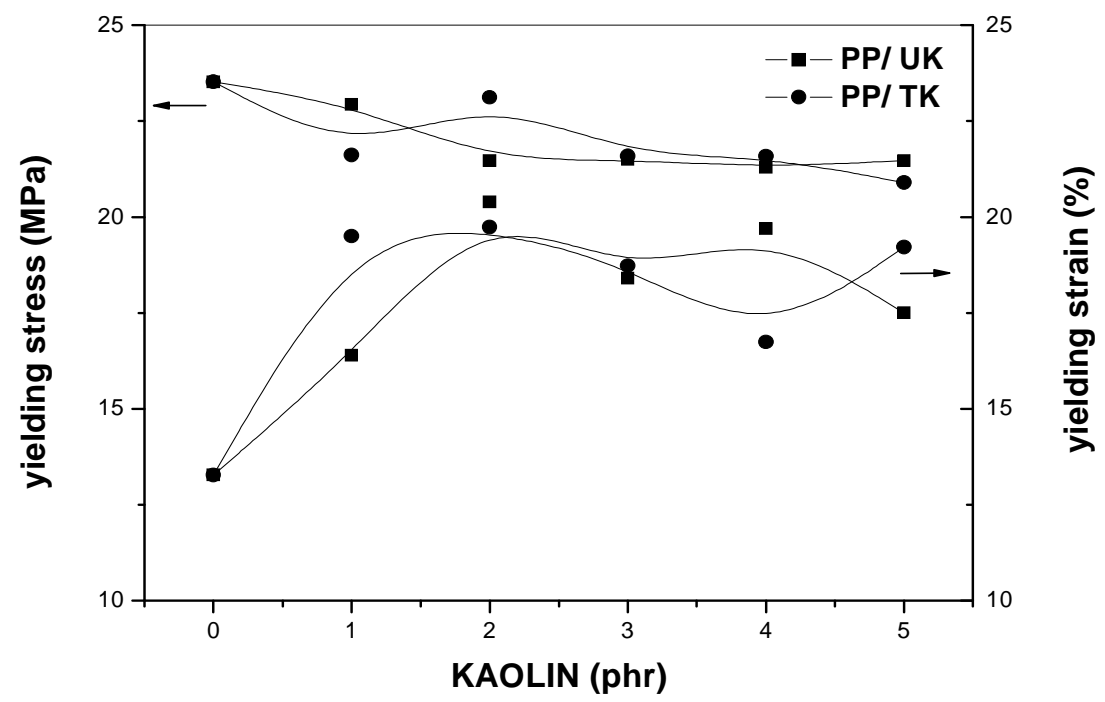

Fig.9. PP composites yielding stress and strain variations as a function of treated and untreated kaolin concentration

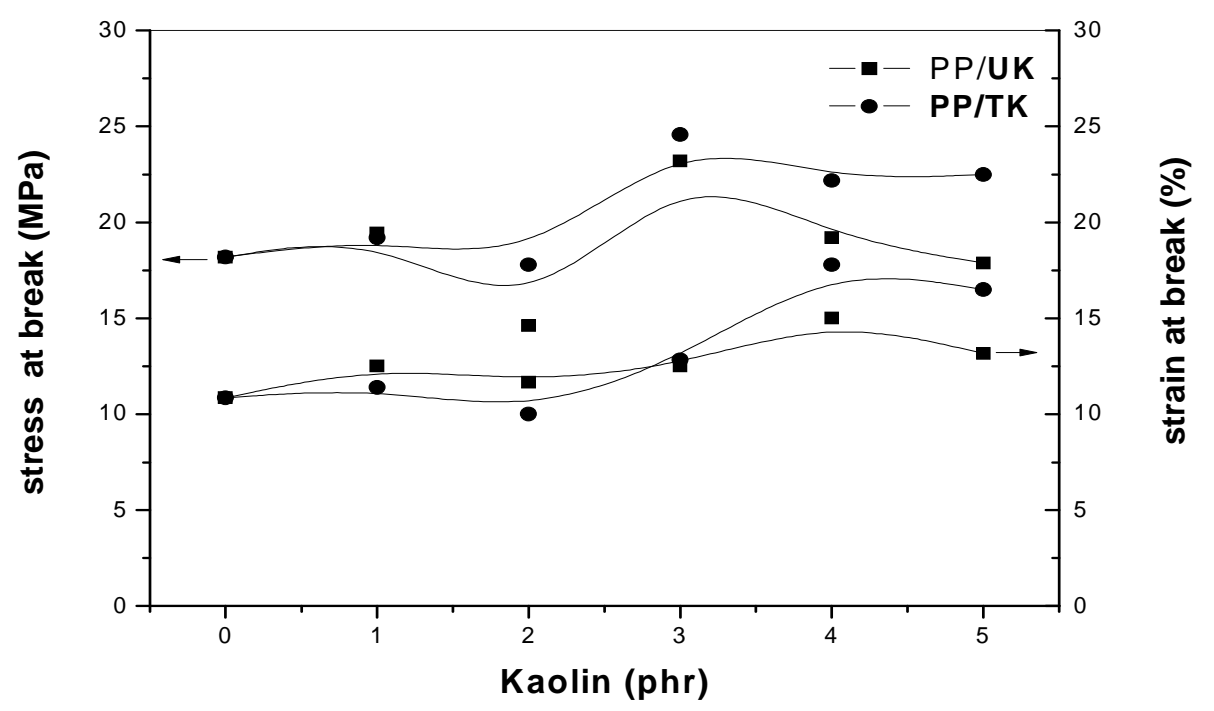

Fig.10. PP composites breaking stress and strain variations as a function of treated and untreated kaolin concentration

\section{CONCLUSION}

Polypropylene/ untreated and treated kaolinite composites have been prepared via direct melt intercalation in an internal mixer. The effect of the untreated and treated kaolinite by alkylammonium salt on the morphology, thermal and mechanical properties of pure polypropylene was investigated. 
Also, the clay samples were XRD to confirm the organophilic nature after modification. It confirmed that the 001 reflection of the clay was not affected by the treatment, which states that the inter actions concerned essentially the superficial groups of kaolinite via an adsorption process. MFI index results of composites show a slight variation of the values of the index of fluidity compared to that of the matrix. And due to the treatment of kaolinite with HDTMA, the MFI values of PP/TK are higher than those of the PP/UK composites.

SEM micrographs show poor dispersion of used nanoclay in polypropylene matrix.

DSC results show that thermal properties of the polypropylene has not been effected much by addition of treated and untreated kaolinite and there was no significant changes in on the crystallinity and on the melting temperature of the matrix $X_{c}, T_{c}$ and $T_{m}$, Also, the TGA results confirmed a slight enhancement of the thermal stability of the composites relative to the neat matrix and the bonding of alkylammonium to its groups.

The mechanical characterization showed the decease of the PP/kaolin composites impact strength due to aggregates formation and to the poor adhesion between the filler surface and the matrix. In the opposite, small variations were observed on the tensile characteristics.

\section{ACKNOWLEDGEMENTS}

I want to thank everyone who helped me to make this modest work, starting with the promoter with special tips as well as people working in laboratories where I realized the tests.

\section{REFERENCES}

[1] Jo B W, Park S K, and Kim D K. Mechanical Properties of Nano-MMT Reinforced Polymer Composite and Polymer Concrete. Construction and Building Materials., 2008,22, 14-20.

[2] Wang Y, Wang J J. Shear yield behavior of calcium carbonate-filled polypropylene," Polymer Engineering and Science., 1999, 39(1), 190-198.

[3] Lee H, S Kim, Song J E, and Kim H. Thermal Properties of Maleated Polypropylene/Layered Silicate Nanocomposites, International Journal of Thermoplastics., 2004, 25, 1585-1595.

[4] Rimdusit S, Smittakorn W, Jittarom S and Tiptipakorn S. Highly Filled Polypropylene Rubber Wood Flour Composites, Engineering Journal.,2011, 15,17-30.

[5] Duca J, Kaolin. In. Functional Fillers for Plastics, (Ed) Wiley-VCH, Verlag, New York 2005, pp.221-239. 
[6] Frost R L, Kristof J, Schmidt J, and Kloprogge J T. Raman Spectroscopy of Potassium Acetate-Intercalated Kaolinites at Liquid Nitrogen Temperature, Spectrochimica Acta., 2001, 57, 603-609.

[7] Frost R L, Kristof J Rintoul, L, and Kloprogge J T. Raman Spectroscopy of Urea and Urea-Intercalated Kaolinites at 77K, Spectrochimica Acta., 2000, 56, 1681-1691.

[8] Frost R L, Kristof J, Horvath E, and Kloprogge J T. Effect of Water on the FormamideIntercalation of Kaolinite, Spectrochimica Acta., 2000, 56, 1711-1729.

[9] Deng Y, Dixon J B, and White G N. Molecular Configurations and Orientations of Hydrazine Between Structural Layers of Kaolinite, Journal of Colloid and Interface Science., 2003, 257, 208-227.

[10] Janek M, Emmerich K, Heissler S, and Nüesch R. Thermal Induced Grafting Reactions of Ethylene Glycol and Glycerol Intercalates of Kaolinite, American Chemical Society., 2007, 19, 684-693.

[11] Olejnik S, Posner A, and Quirk J P. the Intercalation of Polar Organic Compounds into Kaolinite, Clay Minerals., 1970, 8, 421-434.

[12]Letaif S, Elbokl T A, and Detellier C. Reactivity of Ionic Liquids With Kaolinite: Melt Intersalation of Ethyl Pyridinium Chloride in an Urea-Kaolinite Pre-intercalate, Journal of Colloid and Interface Science., 2006, 302, 254-258.

[13] Roses A L, Marsili E, Nieuwlaar E, and Patel M K Environmental and Cost Assessment of a Polypropylene Nanocomposite, Journal of polymer environnement., 2007, 15, 212226.

[14]Luyt A S, Dramicanin M D, Antic Z, and Djokovic V. Morphology, mechanical and thermal properties of composites of polypropylene and nanostructured wollastonite filler, Polymer Testing., 2009, 28( 3), 348-356.

[15]Njuguna J, Pielichowski K, and Desai S. Nanofiller-reinforced polymer nanocomposites Polymers for Advanced Technologies., 2008, 19 (8), 947- 959.

[16]Lopez-Quintanilla M L, Sanchez-Valdes S, Devalle L F R, and Medellin-Rodriguez F J. Effect of some compatibilizing agents on clay dispersion of polypropylene-clay nanocomposites, Journal of Applied Polymer Science., 2006, 100 (6), 4748-4756.

\section{How to cite this article:}

Meziane O, Bensedira A, Guessoum M and Haddaoui N. Polypropylene-modified kaolinite composites: effect of chemical modification on mechanical, thermal and morphological properties. J. Fundam. Appl. Sci., 2016, 8(2), 494-509. 